\title{
Marxismo, Psicoanálisis y Trabajo Social. Comentario a la ponencia central de José Paulo Netto
}

\section{Marxism, Psychoanalysis and Social Work. Comment to José Paulo Netto's central conference}

\author{
Prof. SAúl Karsz \\ El profesor Saúl Karsz es miembro de la Asociación Prácticas Sociales de París. 23, rue Albert Legrand 94110 arcueil/France; \\ saulkarsz@wanadoo.fr
}

\begin{abstract}
Resumen
El autor en su respuesta a José Paulo Netto enfatiza el rol de psicoanálisis en la explicación y actualización de la problemática marxista; lo cual supone un doble encuentro, del psicoanálisis con el marxismo, del marxismo con el psicoanálisis; en este encuentro Karsz señala que las prácticas del trabajo social enseñan que ideología e inconsciente no son dos universos impermeables, sino apenas dos dimensiones especificas de un solo y único sujeto humano.
\end{abstract}

-Palabras clave (Marxismo, psicoanálisis, estructura, sexualidad, trabajo social)

\begin{abstract}
The author in his response to Jose Paulo Netto emphasizes the role of psychoanalysis to explain and update the Marxist problematic, which supposes a double meeting of psychoanalysis with Marxism, the Marxism with psychoanalysis. In this meeting Karsz indicates that social work practices teach that ideology and unconscious are not two impenetrable universes, but only two specific dimensions of a single human subject.
\end{abstract}

Key words (Marxism, psychoanalysis, structure, sexuality, social work)

¡Buenos días! Un placer estar aquí, con vosotros, se suma el honor de comentar la ponencia de José Paulo Netto. Comentario rápido, puesto que dispongo de 20 minutos solamente, pero, espero, suficientes para contribuir a la discusión oral, en este recinto, en los pasillos, y más tarde, en la cabeza y en la práctica de las personas aquí presentes. Si les hablo en español (nací en Argentina), disculpen si de vez en cuando aparece alguna fórmula en francés, lengua y país de adopción desde hace ya varias décadas. ¡Vamos al grano, pues!

Primera puntualización sobre esta ponencia de Netto, a partir por supuesto de lo que he comprendido: se trata de una ponencia alta y rotundamente discutible. Lo cual no constituye en absoluto un inconveniente, porque en realidad hay pocos trabajos escritos $\mathrm{u}$ orales que sean discutibles, que valga la pena discutir, y de cuya discusión quepa deducir nuevas pistas, entrever horizontes inéditos. Considero que los lugares comunes, las evidencias, las frases atiborradas de vocablos pseudo-técnicos que nadie se preocupa de definir, no son para nada discutibles. Lo más sano es esperar que se agoten: los lugares comunes no duran cien años, a la diferencia de la lluvia según García Márquez. Es cierto, sin embargo, que nuevos o viejos lugares comunes suelen volver a llover... Ponencia discutible, pues. Por ello quisiera proponer algunas críticas constructivas, para facilitar las aperturas indicadas hace un momento.

Segunda puntualización: la cuestión del marxismo, referencia básica en la exposición de José Paulo. Propondría, sin embargo, una cierta prudencia cuando hablamos de "el marxismo" en singular: so pena de olvidar que lo han atravesado toda suerte de corrientes y de tendencias, que lo siguen atravesando, en el plano teórico, político, ideológico, e inclusive en lo que se refiere a la subjetividad de quienes se adhieren a él. Y aunque todo el mundo, o casi, pretende tener una opinión sobre el mar- 
xismo, pocos explican de qué marxismo se trata, según qué obras, en favor o en desmedro de qué realizaciones concretas... Son numerosos los que se dicen marxistas - como una buena parte de los que se adhieren al psicoanálisis- pero contribuyen a su desaparición precisamente cuando creen haber encontrado en el uno o en el otro un substituto laico de la verdad revelada. Olvidando que no se trata de un bloque, sino de un movimiento, de un proceso dialéctico. Dos ejemplos breves. En su respuesta a una discípula rusa que lo interroga sobre las condiciones de la revolución socialista en $\mathrm{Ru}$ sia, Marx responde... que no puede responderle, porque no ha estudiado suficientemente el tema, y agrega este enunciado "iyo no soy marxista!". Otro ejemplo: los conceptos de clases sociales y de lucha de clases funcionan a lo largo de la obra de Marx sin que éste explicite demasiado su lógica, sus articulaciones y relaciones múltiples, sus efectos: de esto se ocuparía un importante capítulo de El Capital, su obra teórica mayor. Se ocuparía, digo, porque Marx murió habiendo escrito apenas unas pocas líneas a propósito de lo que era y sigue siendo un concepto central. ¡Un autor serio y definitivo hubiera por lo menos terminado su capítulo! Mediante esta abrupta ironía me propongo determinar que la teoría marxista es un trabajo sin fin, una construcción incesante. Imperfección congénita del marxismo, válida igualmente para la física, la geografía, el psicoanálisis: igarantías anti-esclerosis! Marx, al forjar un poderoso cuerpo teórico, tiene razón en muchas cosas porque en varias otras se equivocó, le faltaron datos, no fue muy lejos, no tuvo tiempo o no supo hacerlo... Se trata de una problemática, de una manera de pensar, de tratar de pensar. Utilizarlo como dogma, callando sus puntos ciegos, sus necesarias lagunas, dejando de lado las ironías que aparecen más de una vez en Marx, puede ser tranquilizador para sus adeptos, ipero desastroso para el pensamiento, para la crítica argumentada del mundo actual y para el esbozo de un mundo diferente!

Tercera puntualización: hoy día el pensamiento marxista se encuentra en una situación paradójica. Toda suerte de indicios insisten en su radical inconsistencia, en su pura y llana desaparición; referirse todavía a Marx es como confesar una ternura inmoderada por los dinosaurios. Lo cual, sin embargo, no impide que dicha problemática siga siendo indispensable para pensar el orden contemporáneo. No para detallar tal o cual aspecto, hacer un inventario de tal o cual sector económico o político, sino para interrogar su razón de ser, su lógica de conjunto, las razones de su desarrollo. Se rechaza todo Marx como en su momento se rechazó todo Newton: ¡señalo, sin embargo, que incluso los cuerpos que no están de acuerdo con Newton caen también hacia el centro de la tierra! Problemática indispensable, además, para explicar cómo y porqué el trabajo social no puede carecer de "clientes", ni dejar de enfrentarse a situaciones individuales y colectivas que requieren constantemente su intervención. ¿Profesión de porvenir, a su manera?

Tal es, siguiendo el título de esta jornada, el desafío del orden contemporáneo: la sociedad en su conjunto, y el trabajo social en particular, aparecen como enigmáticos, sin lógica aparente, radicalmente "irracionales", si no se acude a análisis orientados por la problemática marxista. Pero, agrego, y esto es igualmente importante, que la sociedad contemporánea tampoco se puede comprender recurriendo únicamente a ese tipo de orientación: el marxismo no constituye en absoluto la explicación última y definitiva de la sociedad capitalista en su faz neoliberal, ni en ninguna otra.

Cuarta puntualización. Por lo que escuchado y leído de los trabajos de José Paulo Netto, no dudo de que coincidimos en esta manera de encarar la problemática marxista. Es por eso, justamente, que quisiera enfatizar problemas de dos órdenes. Por un lado, la suerte reservada a las construcciones no marxistas, me refiero a las así llamadas Ciencias Sociales. Éstas se han desarrollado en referencia al marxismo, en alianza con él, en oposición sobre todo, sacando partido de sus insuficiencias reales y-o imaginarias. Diferentes figuras ilustradas por los dos colegas que han comentado previamente, en esta mesa, la intervención de Netto. Relación sobredeterminada, sin duda, que se juega en torno al concepto complejo de clases sociales. ¿Existen hoy día clases sociales? Si no, ¿Qué o quién las rempla$z a$ ? Si no hay clases sociales, ¿Qué lógica organiza las relaciones sociales contemporáneas, a la escala nacional e internacional? Si al contrario, se considera que hoy día hay clases sociales y relaciones de clase, y que éstas condensan el núcleo estratégico del capitalismo en su estadio neoliberal, queda por averiguar cómo existen, de qué manera, según qué modalidades, alianzas y oposiciones, jteniendo en cuenta que de ningún modo vivimos ya en el siglo $\mathrm{XIX}$, ni siquiera en el XX!

Sabemos que una buena parte de la psicología, de la psiquiatría, y la totalidad de las doctrinas conductistas dedican muchísimo tiempo a esqui- 
var el concepto psicoanalítico de inconsciente, empecinadas en remplazarlo por nociones más "educadas", tranquilas, políticamente correctas (en francés se diría: "más católicas"). Del mismo modo, las Ciencias Sociales desarrollan mil subterfugios para esquivar el concepto de clase social, para evitar incluso de decir "clases sociales", o, peor, "lucha de clases": ¡como si fueran palabras malditas!

¿Deduciremos que las Ciencias Sociales se equivocan rotundamente, en la medida en que escamotan un punto esencial, y que debemos por tanto expulsarlas de los análisis de la sociedad contemporánea y no tomarlas para nada en cuenta en las prácticas concretas del trabajo social?

Sin embargo, como por el marxismo, evitemos las simplificaciones. El catecismo es estructuralmente estereotipado y aburrido, más aun cuando se pretende progresista. Las Ciencias Sociales, preocupadas por cómo funcionan los individuos, los grupos, las instituciones, pero poco interesadas en saber por qué funcionan así y qué es lo que realmente funciona, producen al mismo tiempo numerosas observaciones, análisis y descripciones sumamente instructivas, finalmente irremplazables... Si estas disciplinas no tienen fundamentalmente la razón, tienen sin embargo varias y sólidas razones para desarrollarse de manera relativamente autónoma: la problemática marxista no explica todo porque la realidad es demasiado compleja para aprisionarla en una sola malla. Desde el punto de vista materialista y dialéctico que defiendo acá, la realidad no es subsumible en ninguna teoría. Lo real no es en absoluto soluble en el concepto. Se puede y hasta se debe conocer la realidad natural, la realidad histórica, la realidad subjetiva, como nos lo muestra la historia de las ciencias. Historia hecha de avances extraordinarios y de perdurables impasses. La ciencia es un trabajo, el cientismo es una religión.

Lección de los tiempos modernos: no hay Discurso de la Verdad, salvo en ciertos lugares más o menos tétricos, pero sí hay discursos con algunas verdades, discursos que se construyen, se rectifican, se modulan, se perfeccionan, y quedan por definición incompletos. A igual distancia del dogmatismo sin matices y del eclecticismo sin principios.

Surge aquí un segundo orden de problemas: a propósito de la dialéctica y del rol de la contradicción. Desde el punto de vista de las Ciencias Sociales, la contradicción desempeña un rol nefasto. Desde el sentido común, aparece como un sinónimo de incongruencia y de absurdo. A partir de una postura dialéctica, la contradicción, las contradicciones revisten un rol positivo de motor, de posibilidad de apertura y de porvenir. ¡Sin contradicción, estamos muertos! Quisiera mostrarlo volviendo a la exposición de José Paulo.

Quinta puntualización. ¿Catastrofismo? Netto analiza el estado de bienestar en términos de situación de excepción en la larga historia del capitalismo, de ruptura en su historia supuestamente lineal e implacable. Análisis equívoco, en mi opinión. No se trata de una excepción, sino más bien de una contradicción en el sentido dialéctico de este vocablo. No un accidente fortuito, ni un paréntesis coyuntural, sino el resultado histórico -o sea estable e inestable- de relaciones de fuerza, alianzas y oposiciones entre clases y grupos sociales. Debido a que el capitalismo está plagado de tensiones y contradicciones, el estado de bienestar fue posible y necesario. Se trató $-y$ sigue tratándose, porque no ha desaparecido completamente- de una de las tendencias internas al capitalismo, como el neoliberalismo -otra de sus tendencias internas- ocupa hoy día un lugar hegemónico. Pero el estado de bienestar tampoco representó una ruptura en la historia del capitalismo, sino una reorganización inédita de las relaciones sociales, una modalidad particular del capitalismo (el pacto fordista): la redistribución de una parte de la riqueza social que caracteriza al estado de bienestar no altera en absoluto las relaciones entre clases y grupos sociales, el lugar ocupado por unos y otros en la organización social. No se trata de una excepción, sino de una confirmación...

Creo que al no dar a la contradicción un rol motor, o suficientemente motor, José Paulo subestima el dinamismo del capitalismo, su capacidad de adaptación y readaptación. Y tal vez nos dé una imagen esencialista, poco dialéctica...

Una opinión corriente sostiene que la sociedad contemporánea esta en crisis. ¡Pésima metáfora! La situación es grave porque el neoliberalismo es una salida de crisis puesto que produce un reacomodamiento de las relaciones sociales, de las relaciones capital-trabajo, una producción extraordinaria de riquezas a la escala planetaria, una naturalización de las desigualdades sociales. Las sociedades europeas, las americanas del norte, y, por lo que sé, buena parte de las sociedades latinoamericanas, están bien e incluso muy bien... para ciertos grupos y fracciones de clase, al mismo tiempo que están mal e incluso terriblemente mal para otros grupos y fracciones de clase. No se trata de la sociedad en 
general, sino de la sociedad vista desde la perspectiva económico-política de tal o cual grupo. Dato esencial, a partir del cual se puede repensar esta categoría de crisis.

Y llego por fin al trabajo social. Para señalar, ante todo, que lo que puede inquietar, sino desesperar a muchos trabajadores sociales es la crisis de una cierta representación de la sociedad en la que se creía vivir. No es la sociedad real quien anda mal, ésta anda tan bien y tan mal como hace un siglo. Son las modalidades de este andar bien y de este andar mal las que cambian, y quedan por analizar. Se halla en crisis una representación del bienestar, la idea de una salida durable de la pobreza, del acceso a la vivienda para todos, a los bienes culturales, se halla en crisis la ilusión de un progreso general y generalizado...

Me parece indispensable que tomemos consciencia de la situación real para que, pese a todo, las intervenciones sociales continúen provocando algún efecto benéfico. Si persistimos en un esquema que trata de las condiciones estructurales del capitalismo pero sin tener suficientemente en cuenta sus tensiones y contradicciones, no veo bien qué se puede hacer en trabajo social, qué se puede hacer con el trabajo social. Salvo repetir declaraciones llenas de buena voluntad humanista pero finalmente bastante cursis, sobre la ayuda a los pobres, la asistencia a la gente con problemas materiales y-o psíquicos, la defensa de la dignidad humana, etcétera, etcétera. Por supuesto que está muy bien ayudar a los pobres, pero no por esto saldrán de la pobreza, como máximo tal vez puedan aguantarla un poco mejor. Abolir la pobreza es una alternativa improbable en el marco del capitalismo, sobre todo en su fase neoliberal.

No cabe denunciar al trabajo social porque, en efecto, éste es incapaz de resolver los problemas de vivienda, de pobreza, de salud física o mental, de mujeres maltratadas, de escolaridad... Incapaz de resolverlos porque estos problemas se generan en otras esferas, en otros mundos económicos y políticos, a los que el trabajo social no tiene acceso. Evitemos de culpabilizar inútilmente a los trabajadores sociales, aunque sólo sea porque en nuestra tradición judeo-cristiana ya somos culpables "naturalmente".

Por supuesto que el trabajo social es un aparato del Estado, del Estado burgués, - salvo que en mi boca "burgués" no es un insulto, ni un cumplido tampoco. Es simplemente un concepto, que com- porta conocimiento, saber, argumento. Y que cabe discutir. Y que, en todo caso, no es un calificativo moral: los burgueses no son malos por definición, como tampoco los pobres son angélicos por nacimiento. Por supuesto que ningún sistema social financia profesionales e instituciones para que difundan la subversión, ni siquiera -como Paulo Freire por ejemplo- para contribuir a la "concientización" de las masas populares. Imprescriptible condición estructural. Que sin embargo no constituye para nada una fatalidad que condena de una vez para siempre al trabajo social, ni un destino al que irremediablemente los trabajadores sociales deben someterse. Los asalariados del capitalismo no siempre son sus cómplices. No hay fatalidad porque, insisto, el capitalismo está atravesado por corrientes y tendencias contradictorias, y también porque queda a cada trabajador social asumir el compromiso ético de la adhesión, o de la sumisión, o de la resignación, o bien de la lucha empecinada por ideales que nadie le financia pero que él y otros consideran impostergables.

El trabajo social se ocupa de ciertos efectos domésticos del capitalismo, en términos de vida conyugal, escolar, laboral, subjetiva. Los llamo "efectos ideológicos”. La clínica de la intervención social -que trato de impulsar trabajando con equipos e instituciones- consiste en identificar esos efectos, lo que en ellos se pone en juego, y en la detección de vías alternativas que quepa explorar.

¿Qué hacer -me dicen- de la esperanza que orienta a numerosos trabajadores sociales, al comienzo de su carrera al menos? Es cierto que hoy día hay cada vez menos lugar para la esperanza porque quien busca esperanza debe dirigirse al lugar propicio (iglesia, mezquita, sinagoga) y conformarse a las prácticas que allí se le inculquen. Ese lugar no será un congreso sobre trabajo social, ni esas prácticas la labor concreta de los trabajadores sociales. Suministrar esperanza a la gente no tiene nada que ver con la intervención social, ni con la política social, ni con la toma de posición individual y colectiva, con el compromiso ético. Lo realizable, lo concretamente realizable es proponer elementos de lucidez, de "lucidificación" si me permiten...

¿Cuál es la opción real del trabajador social sobre el terreno?, me preguntan. Responderé en términos de dosis, es decir de tendencias: ¿En qué medida pongo en obra prácticas de control más o menos policíaco, de examen de moralidad, de cruzada que ignora toda duda y se ahorra toda interrogación? ¿Y en qué medida, por el contrario, 
mis prácticas hacen posible procesos de liberación de los que no soy el autor mesiánico pero a los que contribuyo con empecinamiento y múltiples limitaciones? Rol precioso, en este sentido, de un trabajo clínico que incluya la dimensión psíquica pero dé la misma importancia a las dimensiones políticas, culturales, económicas: en la sociedad, y también en las relaciones de pareja, en el hogar, en la sala de clase, en la entrevista con una familia..

Tal es, a mi manera de ver, el dilema determinante: ¿En qué medida nos autorizamos a desarrollar márgenes de maniobra respecto de la política social que nos emplea, de la que no somos para nada culpables pero de las que somos en mayor o en menor parte responsables, según las prácticas que ponemos en obra, según los efectos que provocamos?

El discurso marxista, en la medida en que no renuncia a la cuestión del porqué, reviste aquí una importancia decisiva, en términos de elucidación de estructuras, de identificación de funcionamien- tos, de diseño de estrategias y de puestas en juego. A condición de mantener la distancia -jamás definitiva- entre saber y doctrina, entre investigación y revelación.

En esta actualización de la potencia explicativa de la problemática marxista, el psicoanálisis juega un papel central. Porque las estructuras sociales no explican todo, y porque en las clases sociales y entre ellas circula sexualidad, o sea amores y odios, pulsión de vida y pulsión de muerte...

Esto supone un doble encuentro, del psicoanálisis con el marxismo, del marxismo con el psicoanálisis. Un trabajo paciente de enseñanza recíproca. Hoy día indispensable, en el interés del uno y del otro. Las prácticas del trabajo social nos enseñan que ideología e inconsciente no son dos universos impermeables, sino apenas dos dimensiones específicas de un solo y único sujeto humano. Dos lógicas que es tiempo de considerar simultáneamente. 